\title{
Salivary Pro-Inflammatory Cytokines and Salivary Bacterial Challenge Effect on Dental Caries: A Clinico-Molecular Cross-Sectional Study
}

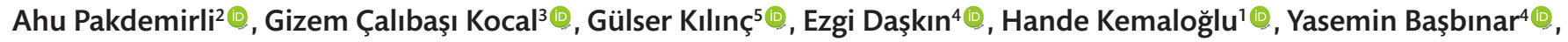 \\ Hülya Ellidokuz ${ }^{6}$ )
}

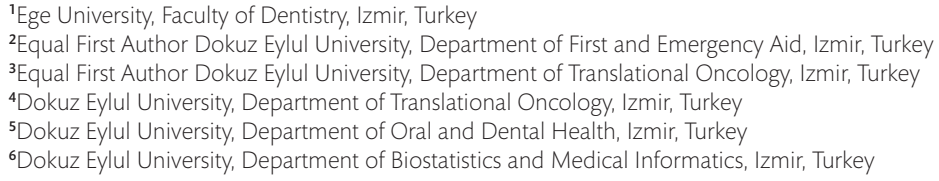

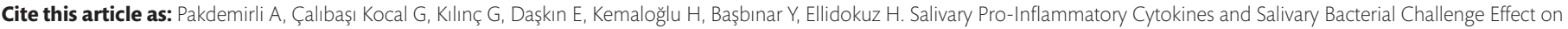
Dental Caries: A Clinico-Molecular Cross-Sectional Study. J Basic Clin Health Sci 2020; 1:77-81.

\begin{abstract}
Objectives: Objective of this study is to determine the correlation between salivary cytokine concentrations and cariogram value high (C1) and low (C2) experience in people. In this direction, saliva cytokines showed a significant correlation with the patient's caries experience.

Patients and Methods: Unstimulated whole saliva samples were collected from 38 appropriate populations of patients aged between 20 to 57 years old. All patients' DMF (decay/missing/filled) values were higher than 0 . Twenty-one caries activity groups (C1) and 17 caries nonactivity groups (C2) patients were collected for this study. Procedures of the clinical evaluation were the collection of saliva samples and oral examination. The whole saliva from 38 patients with C1 and C2 was investigated for the existence of GM-CSF, TNF $\alpha$, IFN-g, IL-2, IL-4, IL-6, IL-8, and IL-10.

Results: The study population consisted of 38 subjects with a mean age of $34.76 \pm 14.43$ years. Likewise, there was a significant interaction between salivary flow rate, S. Mutans number, number of Lactobacillus, number of meals and IL-6, a significant difference in caries activity groups.

Conclusion: Salivary cytokines demonstrated significant interactions to caries experience of the patient.

Keywords: Salivary, Streptococcus mutans, Pro-inflammatory cytokines, Dental caries
\end{abstract}

\section{INTRODUCTION}

Multifactorial etiology generates dental caries which is an infectious disease (1-3). Up to date numerous studies have investigated these etiological factors and their impacts on the disease $(2,4)$. Even though the interactions between pathological (acidogenic bacteria, fermentable carbohydrates) and protective factors (saliva components: proteins, fluoride, calcium, phosphate), are complex, the disease can easily be prevented if the dynamic balance between the protective and pathological factors can be kept in equilibrium $(3,5,6)$. Mutans streptococci, and Lactobacilli are the two important caries associated acidogenic bacteria of dental caries $(1,4)$. An increase in the numbers of $S$. Mutans in saliva is associated with caries initiation where as an increase in the number of lactobacilli indicates progressed lesions of caries (7).
The cariogram index was developed to identify people prone to tooth decay development in societies and to provide protective and appropriate therapeutic services to stop disease in these individuals, to visually demonstrate the risk of tooth decay and the relationship between bacterial diet and host response. The assessment of dental caries risk in this index is quite simple (8). In their study, Petersson et al. reported that the best way to explain decay formation in children is the dietary frequency, the use of fluorine preparations, salivary flow rate, buffering capacity, the number of Lactobacilli and S. Mutans in saliva, the amount of plaque and the effectiveness of the cariogram program in determining the caries risk (9).

In addition to bacteriological factors, salivary components and response of immunocompetent cells are also important for caries 
development. As a result, bacterial colonization accompanying the advance of dental caries, local defense factors are activated and inflammation process initiates (10-14). Cytokines are inflammatory negotiator of the immune system. Cytokines are systematically released due to bacterial colonization and invasion $(15,16)$.

Recent studies show that cytokines are important in regulating the inflammatory response to bacterial infection $(4,11,14,17$ 21). Cytokines role in dental caries formation is not yet fully understood. However, investigators are aware of the fact that $S$. mutans found in the mouth stimulate pro-inflammatory cytokines $(4,22)$. It has been reported that the cytokines levels (TNF- $\alpha$, IL-6 and IL-8) are significantly increased in the saliva of those with dental caries compared to those without $(15,23,24)$.

The purpose of this study was to detect the levels of several cytokines in salivary related to caries experience.

\section{MATERIALS AND METHODS}

\section{Ethics}

The research protocol was authorized by the Ethical Committee of Dokuz Eylul University (2013/36-07 date 10.03.2013) with written informed consent from all participants.

\section{Participants}

The study included 38 patients aged 20-57 years. Participants with systemic diseases and those who had used antibiotics during the previous 3-months period were eliminated.

\section{Methods Used to Obtain the Desired Sample}

Questionnaires

Detailed data were collected on general health, dietary and oral hygiene habits of the attendants to be used in Cariogram software via structured questionnaire. Diseases were taken into account only if it influenced the caries process directly or indirectly. Diet frequency, number of mealtimes, snacks and their contents of unfavorable carbohydrates were questioned in detail. Questionnaire was also employed to collect data on habit of tooth brushing, frequency, the usage of fluoride toothpaste and the other supplements.

\section{Clinical Dental Examination}

Oral examinations of the patients were performed by a dentist using a mirror sond and periodontal sond in a clinical setting. The DMFT (decayed/missing/filled teeth) were reported and caries experience was expressed as DMFT in accordance with World Health Organization criteria (18). No radiographs were taken. All participants classified according to DMFT score (19). Oral hygiene was evaluated by scoring dental plaque amount according to the Silness and Löe index (20). The kappa co-efficient value was 0.94 for Silness and Loe plaque index and 0.92 for DMFT.

\section{Saliva Sampling}

Salivas were obtained by the standard method. Subjects' samples were collected between 9:00 and 11:00 a.m. Saliva samples were obtained from all participants and they were warned not to chew gum, drink or eat two hours before the evaluation time. Before starting to collect the stimulated saliva, the participants were requested to chew paraffin and swallow the first portion of saliva. Then, saliva was stimulated by chewing paraffin for 5 minutes and then collected under resting conditions into a plastic cup. The flow rate was calculated in $\mathrm{ml} / \mathrm{min}$.

\section{Saliva buffering capacity}

CRT (Caries Risk Test) buffer strips (Ivoclar-Vivadent, Schaan, Liechtenstein) were used to test buffer capacity of saliva. A drop of saliva was taken from the cup, and dispensed onto a test strip. After waiting for 5 minutes, the final color was detected and compared with the colored scale assigned by the manufacturer to be able to assess the buffering capacity (yellow color means low buffering capacity, green color means medium buffering capacity and blue color means high buffering capacity).

\section{Microbiological analysis}

Determining the $S$. mutans and lactobacilli levels in $1 \mathrm{~mL}$ of saliva, a CRT bacteria kit (Ivoclar Vivadent, Schaan, Liechtenstein) was used. Two surfaces (for S. mutans and lactobacilli) of agar carriers in the kit were completely wetted with saliva using a pipette and the carriers were slided in their vials. After placing the vials into the incubator at $37^{\circ} \mathrm{C}$ for 48 hours, comperation of the lactobacillus and S. mutans density was occurred from enclosed model chart's corresponding evaluation pictures. The lactobacilli and $S$. mutans count in salivary were measured semi-quantitatively and the number of colonies forming units (CFU) was used for determination. The density of colonies was compared with a chart and classified using four categories. Results were stated as two values: $<105$ CFU and $\geq 105$ CFU.

\section{Caries risk assessment (Cariogram)}

Nine of the ten original Cariogram variables were used in this study. Calculation of the caries risk of each participant was made in Cariogram computer program from the described informations above. The scored data from the clinical examinations and the questionnaire were entered in the Cariogram software.

Cariogram program evaluates the risk of future caries activity and states the results as possibility of prevent caries. Nine factors/ parameters of direct relevance to caries are entered into the computer program to create a Cariogram (9). The various parameters are given a score according to predetermined scales for each factor (Table 1). The chance to avoid caries was finally grouped in threelevels: low chance $0 \%-20 \%$ (high caries risk), moderate chance $21 \%-60 \%$ (moderate caries risk), and high chance 61\%-100\% (low caries risk).

\section{Multiplex saliva cytokines analysis}

The specific cytokines that were studied include: Tumor Necrosis Factor alpha (TNF $\alpha$ ), IFN-g, GM-CSF, IL-2 (Interleukin 2), IL-4 (Interleukin 4), IL-6 (Interleukin 6), IL-8 (Interleukin 8) and IL-10 (Interleukin 10).

The Luminex XMAP $^{\mathrm{TM}}$ salivary assays were performed in 96-well plate. Analytes were preferred on pathophysiology cases which described in the literature (6).

Human Cytokine Group 1, 8 plex Panel (Bio-Rad Laboratories Inc. USA) was carried out according to Bio-Plex Pro assays instruction 


\begin{tabular}{|c|c|c|}
\hline Factor* & Info/data needed & Score \\
\hline Caries experience & $\begin{array}{l}\text { DMFT, DMFS, new caries experience } \\
\text { in the past } 1 \text { year }\end{array}$ & $\begin{array}{l}\text { 0: DMFT=0 } \\
\text { 1: Good oral health status } \\
\text { 2: Normal oral health status } \\
\text { 3: New caries in the past year }\end{array}$ \\
\hline Related diseases & General health questionnaires & $\begin{array}{l}\text { 0: No systematic illness } \\
\text { 1: Systematic illness that contributes moderately to caries risk } \\
\text { 2: Serious systematic illness with strong influence on caries }\end{array}$ \\
\hline Diet, contents & $\begin{array}{l}\text { Lactobacillus count and sugar content } \\
\text { of diet }\end{array}$ & $\begin{array}{l}0:<1000 \text { colony-forming units per } \mathrm{MI}(\mathrm{CFU} / \mathrm{ml}) \text { and very low sugar consumption } \\
\text { 1: } 10^{4} \mathrm{CFU} / \mathrm{ml} \text { and low sugar consumption } \\
\text { 2: } 10^{5} \mathrm{CFU} / \mathrm{ml} \text { and moderate sugar consumption } \\
3:>10^{6} \mathrm{CFU} / \mathrm{ml} \text { and high sugar consumption }\end{array}$ \\
\hline Diet, frequency & Number of intakes per day & $\begin{array}{l}0: \text { Maximum } 3 \text { intakes / a day } \\
\text { 1: } 4 \text { or } 5 \text { intakes / a day } \\
\text { 2: } 6 \text { or } 7 \text { intakes / a day } \\
\text { 3: over } 7 \text { intakes / a day }\end{array}$ \\
\hline Plaque amount & Plaque index & $\begin{array}{l}\text { 0: No plaque } \\
\text { 1: Plaque visible on using to probe } \\
\text { 2: Plaque visible to the naked eye } \\
\text { 3: Plaque all around the tooth }\end{array}$ \\
\hline S. mutans count & CRT Bacteria culture & $\begin{array}{l}\text { 0: First area of manufacturer's chart } \\
\text { 1: Second area of chart } \\
\text { 2: third area of chart } \\
\text { 3: Fourth area of chart }\end{array}$ \\
\hline Fluoride program & Oral health questionnaires & $\begin{array}{l}\text { 0: Flouride tothpaste and constant use of additional fluoride measures } \\
\text { 1: Flouride tothpaste + occasional use of additional measures } \\
\text { 2: Flouride tothpaste only } \\
\text { 3: Flouride not used in any form }\end{array}$ \\
\hline Saliva secretion & Stimulated saliva test-secretion rate & $\begin{array}{l}0:>0.7 \mathrm{ml} \text { saliva / minute } \\
1: 0.3-0.7 \mathrm{ml} \text { saliva / minute } \\
2:<0.3 \mathrm{ml} \text { saliva / minute }\end{array}$ \\
\hline Saliva buffer capacity & CTR Buffer & $\begin{array}{l}0: \mathrm{pH}>6 \\
1: \mathrm{pH} 4.5-5\end{array}$ \\
\hline
\end{tabular}

manual. Firstly, $50 \mu \mathrm{l}$ of $1 \mathrm{x}$ beads were added to the assay plate and wells were washed 2 times with $100 \mu$ l washing buffer afterwards. $50 \mu$ l of the sample was added to each well. Subsequently, the plate was incubated for an hour in dark at RT with shaking at 300 RPM and washed three times with washing buffer. Next, $25 \mu \mathrm{l}$ of the antibody diluted was added to each well and incubated for 30 min. Then the plate was washed 2 times with $100 \mu$ l wash buffer again. $50 \mu$ of diluted Streptavidin-PE was added to each well and incubated for 30 minutes. Lastly, the plate was washed again with $120 \mu \mathrm{l}$ of the assay buffer. Concentrations were measured with both Bio-Plex Manager and Luminexx PONENT software (Bio-Rad Laboratories Inc.USA).

\section{Statistical Analysis}

Whole datas were analyzed by using the Statistical Package for the Social Sciences (SPSS) for Windows (version 15.0; SPSS Inc., Chicago, IL, USA). Mean values, standard deviations median (minmax) were calculated for age, cariogram, saliva buffering capacity, cytokine concentrations, and the salivary flow rate. Associations of saliva concentrations of TNF $\alpha$, GM-CSF, IFN-g, IL-2, IL-4, IL-6, IL8 and IL-10 with dental caries and S. mutans level were evaluated with the Chi-Square and Mann-Whitney $U$ tests. Any $p$ value of less than 0.05 was considered to indicate statistical significance.

\section{RESULTS}

The participants were 38 patients aged 20-57 years and the mean age of $34.76 \pm 14.43$ years. The DMFT scores for 17 patients were between 1-4, for 21 patients it was below 1 and above 4. Twentyone patients had high (C1) and 17 patients had low caries risk (C2). A statistically significant difference has been observed between C1 and C2 values, caries score, lactobacilli count, number of meals, number of St. Mutans and saliva flow rate $(P<0.05)$, any difference was found between plaque score, fluorine score and buffering capacity $(\mathrm{P}>0.05)$ (Table 2$)$.

Positive correlation was found between IL-6, IL-10 and IFN-g values as the number of caries increased. However, we found statistically significant difference between IL-6 and C1, but no difference between IL-10 and IFN-g. Although the difference was no statistically significant, we observed that IL-10 value was lower in C1 than in C2 (Table 3).

TNF $\alpha$, GM-CSF, IFN-g, IL-2, IL-4, IL-6, IL-8 and IL-10, and the cariogram scores were compared with $\mathrm{C} 1$ and $\mathrm{C} 2$ values. It was determined that there was a statistically significant difference between IL-6 and cariogram scores $(P<0.05)$. However, there was no significant difference between $C 1$ and $C 2$ values between TNF $\alpha$, GM-CSF, IFN-g, IL-2, IL-4, IL-6, IL-8 and IL-10 ( $p>0.05)$. 


\begin{tabular}{|c|c|c|c|c|}
\hline Risk of Dental Caries & Score & C1 (n:21) & C2 (n:1) & $\mathbf{P}^{*}$ \\
\hline \multirow{3}{*}{ Dental Caries Score } & 1 & $4(23.5)$ & $13(76.5)$ & \multirow{3}{*}{0.001} \\
\hline & 2 & $1(33.3)$ & $2(55.7)$ & \\
\hline & 3 & $16(88.9)$ & $2(11.1)$ & \\
\hline \multirow{4}{*}{ Number of Lactobacilli } & 0 & - & $5(100.0)$ & \multirow{4}{*}{0.001} \\
\hline & 1 & $2(22.2)$ & $7(77.8)$ & \\
\hline & 2 & $8(61.5)$ & $5(28.5)$ & \\
\hline & 3 & $11(100.0)$ & - & \\
\hline \multirow{3}{*}{ Number of Meal } & 0 & $4(40.0)$ & $6(60.0)$ & \multirow{3}{*}{0.027} \\
\hline & 1 & $8(44.4)$ & $10(55.6)$ & \\
\hline & 2 & $9(90.0)$ & $1(10.0)$ & \\
\hline \multirow{3}{*}{ Plaque Score } & 0 & $7(53.8)$ & $6(46.2)$ & \multirow{3}{*}{0.946} \\
\hline & 1 & $13(56.5)$ & $10(43.5)$ & \\
\hline & 2 & $1(50.0)$ & $1(50.0)$ & \\
\hline \multirow{4}{*}{ Number of S. Mutans } & 0 & - & $2(100.0)$ & \multirow{4}{*}{0.001} \\
\hline & 1 & $2(20.0)$ & $8(80.0)$ & \\
\hline & 2 & $8(57.1)$ & $6(42.9)$ & \\
\hline & 3 & $11(91.7)$ & $1(8.3)$ & \\
\hline \multirow{4}{*}{ Fluorine Score } & 0 & - & $1(100.0)$ & \multirow{4}{*}{0.238} \\
\hline & 1 & $1(50.0)$ & $1(50.0)$ & \\
\hline & 2 & $1(33.3)$ & $2(66.7)$ & \\
\hline & 3 & $19(59.4)$ & $13(40.6)$ & \\
\hline \multirow{3}{*}{ Saliva Flow Rate } & 0 & $4(25.0)$ & $12(75.0)$ & \multirow{3}{*}{0.001} \\
\hline & 1 & $6(60.0)$ & $4(40.0)$ & \\
\hline & 2 & $11(91.7)$ & $1(8.3)$ & \\
\hline \multirow{2}{*}{ Buffering Capacity } & 0 & $10(47.6)$ & $11(52.4)$ & \multirow{2}{*}{0.342} \\
\hline & 1 & $11(64.7)$ & $6(25.3)$ & \\
\hline
\end{tabular}

Table 3. Saliva cytokine concentrations, according to caries risk groups. C1 is high risk and C2 is low risk group. Mann Whitney $U$ Test was applied.

\begin{tabular}{lccc}
\hline Risk of Dental Caries & $\mathbf{C 1}(\mathbf{n}: \mathbf{2 1})$ & $\mathbf{C 2}(\mathbf{n}: \mathbf{2})$ & $\mathbf{P}^{*}$ \\
\hline $\mathrm{IL}-2(\mathrm{pg} / \mathrm{ml})$ & $1.65 \pm 0.67$ & $1.62 \pm 0.88$ & 0.769 \\
$\mathrm{IL}-4(\mathrm{pg} / \mathrm{ml})$ & $0.14 \pm 0.13$ & $0.15 \pm 0.14$ & 0.848 \\
$\mathrm{IL}-6(\mathrm{pg} / \mathrm{ml})$ & $18.19 \pm 19.92$ & $8.7968 \pm 16.40$ & 0.041 \\
$\mathrm{IL}-8(\mathrm{pg} / \mathrm{ml})$ & $725.71 \pm 864.17$ & $103.62 \pm 2357.14$ & 0.965 \\
$\mathrm{IL}-10(\mathrm{pg} / \mathrm{ml})$ & $7.51 \pm 6.43$ & $9.42 \pm 5.11$ & 0.361 \\
GM-CSF & $36.17 \pm 48.59$ & $46.45 \pm 52.54$ & 0.607 \\
IFN-g & $24.06 \pm 35.62$ & $20.84 \pm 17.27$ & 0.190 \\
TNF $\alpha$ & $4.64 \pm 3.53$ & $4.79 \pm 4.26$ & 0.872 \\
Cariogram value & $37.88 \pm 19.05$ & $11.10 \pm 6.19$ & $<0.001$ \\
\hline
\end{tabular}

There was statistically significant difference, according to nonparametric test in patients with high caries, between IL-2 and GMCSF ( $p<0.001)$, IL-8 with IL-10 ( $p<0.013)$, GM-CSF $(p<0.030)$ and TNF- $\alpha(p>0.020)$ and between GM-CSF and TNF- $\alpha(p<0.027)$.

\section{DISCUSSION}

Microbial, genetic, immunological, environmental factors and behavioral differences play a role in the formation and severity of caries (4). It is observed that the dynamic balance between the pathological factors and protective factors is impaired in the process of dental caries formation and the caries progresses with the pathological factors outweighing the protective factors
(25). The presence of pathogenic microorganisms in the etiology of dental caries is undeniable. However, the oral and dental responses of dental caries in the oral environment require more caution in understanding the pathogenesis of caries.

It is necessary to evaluate the risk of caries to predict whether a new caries will develop, or whether an initial lesion will continue to grow. Therefore, the cariogram index was developed to visually demonstrate the risk of caries and the relationship between bacterial diet and host response (10). The cariogram index can be easily applied by dentists. Bratthall et al. indicate that the index consists of both prediction model and risk models (8).

In the study, a positive correlation was found between the high and low tooth decay patients and the current value. Similarly, many investigators stated that there was a relationship between the current and the caries $(26,27)$. In our study, we also found a positive relationship between the patients with high and low dental caries scores, number of meals and number of Streptococcus mutans but there was a negative relationship between salivary flow rates.

Polypeptide cytokines regulate the immune response and they have great importance in the care of oral health. The colonization of bacteria in the oral cavity begins the inflammation process and inflammatory lesions stimulate the host's natural and adaptive immune response. Prso et al. reported that patients with periapical root lesions had higher IL levels than the control group (28). There are studies indicating that there is a relationship between tooth decay and cytokines and there are other studies that indicate otherwise $(4,29)$.

Gornowicz et al. examined the changes in saliva cytokines of patients with dental caries and compared the results with the control group. The research showed that TNF- $\alpha$, IL-6, and IL-8 were high in unstimulated saliva of people with dental caries (29). Ribeiro et al. in their study between early childhood caries and high-carious mothers with children without caries and mothers without caries, had shown that early childhood caries and highcarious mothers' IL-6 levels were higher.

In contrast to these studies, Cogulu et al. point out that dental caries was not significantly correlated with salivary or serum concentrations of IL-1 $\beta, \mathrm{IL}-1 \mathrm{ra}$, or IL- $10^{4}$. Many studies suggest a strong correlation between IL-6 and dental caries $(17,24,29)$. In our study, we observed that IL-6 and IL-8 levels increased in patients with high caries. Although the level of IL- 8 was not statistically significant, the level of IL- 6 was statistically significant.

In addition, investigators believe that high levels of IL- 6 in saliva may be associated with metabolic disorders, and that increased levels of cytokine in serum may be related to metabolic syndrome and hyperinsulinemia $(17,29)$. Systematic reviews have shown that excessive sugar consumption increases insulin resistance and leads to metabolic disorders. In our study, we may refer to the high level of cariogram and IL-6 levels in patients with high DMFT values, because they do not care for excessive sugar consumption and oral hygiene. Salivary cytokines demonstrated significant interactions to caries experience of the patient. 
Informed Consent: All participants

Compliance with Ethical Standards: Dokuz Eylul University non-interventional researches were provided by the ethics committee $1110-$ GOA/2013

Peer-review: Externally peer-reviewed.

Author Contributions: Concept - AP; Design - AP; Supervision - GCK; Fundings - YB; Materials - HK; Data Collection and/or Processing - GCK; Analysis and/or Interpretation HE; Literature Search - GK; Writing Manuscript - HK; Critical Review - ED

Conflict of Interest: No conflict of interest was declared by the authors.

Financial Disclosure: The authors declared that this study has received no financia support.

\section{REFERENCES}

1. Selwitz RH, Ismail AI, Pitts NB. Dental caries. Lancet 2007; 369:51-59. [CrossRef]

2. Hicks J, Garcia-Godoy F, Flaitz C. Biological factors in dental caries: role of saliva and dental plaque in the dynamic process of demineralization and remineralization (part1). J Clin Pediatr Dent 2003; 28: 47-52. [CrossRef]

3. Fejerskov O. Changing paradigms in concepts on dental caries: consequences for oral health care. Caries Res 2004; 38: 182-191. [CrossRef]

4. Cogulu D, Onay H, Ozdemir Y, et al. Associations of interleukin (IL)$1 \beta$, IL-1 receptor antagonist, and IL-10 with dental caries. J Oral Sci 2015; 57: 31-36. [CrossRef]

5. Featherstone JD. The continuum of dental caries-evidence for a dynamic disease process. J Dent Res 2004; 83: 39-42. [CrossRef]

6. Ribeiro CCC, Pachêco CJB, Costa EL, et al. Proinflammatory cytokines in early childhood caries: Salivary analysis in the mother/children pair. Cytokine 2018; 107: 113-117. [CrossRef]

7. McGrady JA, Butcher WG, Beighton $D$, et al. Specific and charge interactions mediate collagen recognition by oral lactobacilli. J Dent Res 1995; 74: 649-657. [CrossRef]

8. Bratthall D, Hansel Petersson G. Cariogram--a multifactorial risk assessment model for a multifactorial disease. Community Dent Oral Epidemiol 2005; 33: 256-264. [CrossRef]

9. Petersson $\mathrm{GH}$, Bratthall D. Caries risk assessment: a comparison between the computer program 'Cariogram', dental hygienists and dentists. Swed Dent J 2000; 24:129-137. [CrossRef

10. Hahn CL, Best AM, Tew JG. Cytokine induction by Streptococcus mutans and pulpal pathogenesis. Infect Immun 2000; 68: 785-6789. [CrossRef]

11. Izumi T, Kobayashi I, Okamura K, et al. Immunohistochemical study on the immunocompetent cells of the pulp in human non-carious and carious teeth. Arch Oral Biol 1995; 40: 609-614. [CrossRef]

12. Martin FE, Nadkarni MA, Jacques NA, et al. Quantitative Microbiological Study of Human Carious Dentine by Culture and Real-Time PCR: Association of Anaerobes with Histopathological Changes in Chronic Pulpitis. J Clin Microbiol 2002; 40: 1698-1704. [CrossRef]

13. Reeves R, Stanley HR. The relationship of bacterial penetration and pulpal pathosis in carious teeth. Oral Surg Oral Med Oral Pathol 1966; 22: 59-65. [CrossRef]

14. Van Nieuw Amorengen A, Bolscher JGM, Veerman ECI. Salivary proteins: protective and diagnostic value in cariology? Caries Res 2004; 38: 247-253. [CrossRef]
15. Graves DT, Cochran D. The contribution of interleukin-1 and tumor necrosis factor to periodontal tissue destruction. J. Periodontal 2003; $74: 391-401$. [CrossRef]

16. Shang $\mathrm{D}$, Liang $\mathrm{H}$, Wei $\mathrm{S}$, et al. Effects of antimicrobial peptide L-K6, a temporin-1CEb analog on oral pathogen growth, Streptococcus mutans biofilm formation, and anti-inflammatory activity. Appl Microbiol Biotechnol 2014; 98: 8685-8695. [CrossRef]

17. Menon MM, Balagopol RV, Sajitha K, et al. Evaluation of salivary interleukin-6 in children with early childhood caries after treatment. Contemp Clin Dent 2016; 7: 198-202. [CrossRef]

18. World Health Organization, Oral health surveys: basic methods. 4th ed. 1997, Geneva.

19. Oulis CJ, Berdouses ED. Fissure sealant retention and caries development after resealing on first permanent molars of children with low, moderate and high caries risk. Eur Archs Paediatr Dent 2009; 10: 211-207. [CrossRef]

20. Silness J, Löe H. Periodontal disease in pregnancy II Correlation between oral hygiene and periodontal condition. Acta Odonto Scand 2009; 22:121-135. [CrossRef]

21. Laputková G, Schwartzová V, Bánovčin J, et al. Salivary protein roles in oral health and as predictors of caries risk. Open Life Sci 2018; 13: 174-200. [CrossRef] https://doi.org/10.1515/biol-2018-0023

22. Słotwińska SM, Zaleska M. Salivary interleukin-1 $\beta$ and Streptococcus mutans level in oral cavity. Cent Eur J Immunol 2012;37:151-153. [CrossRef]

23. Zhao A, Blackburn C, Chin J, et al. Soluble toll like receptor 2 (TLR-2) is increased in saliva of children with dental caries. BMC Oral Health 2014; 14: 108. [CrossRef]

24. Sharma V, Gupta, N, Srivastava N, et al. Diagnostic potential of inflammatory biomarkers in early childhood caries - A case control study. Clin Chim Acta 2017; 471: 158-163. [CrossRef] https://doi. org/10.1016/j.cca.2017.05.037

25. Doméjean S, White JM, Featherstone JD. Validation of the CDA CAMBRA caries risk assessment--a six-year retrospective study. J Calif Dent Assoc 2011; 39: 709-715.

26. Hansel Petersson G, Twetman S, Bratthall D. Evaluation of a computer program for caries risk assessment in schoolchildren. Caries Res 2002; 36: 327-340. [CrossRef]

27. Hansel Petersson G, Fure S, Bratthall D. Evaluation of a computerbased caries risk assessment program in an elderly group of individuals. Acta Odontol Scand 2003; 61: 164-171. [CrossRef]

28. Prso IB, Kocjan W, Simic $\mathrm{H}$, et al. Tumor necrosis factor-alpha and interleukin 6 in human periapical lesions. Mediators of Inflammation 2007; 2007: 382-410. [CrossRef]

29. Gornowicz A, Bielawska A, Bielawski K, et al. Pro-inflammatory cytokines in saliva of adolescents with dental caries disease. Ann Agric Environ Med 2012; 19 :711-716. 